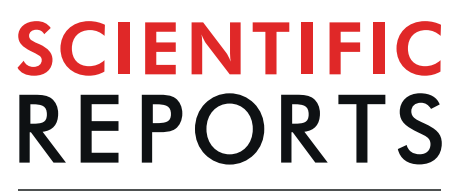

natureresearch

Check for updates

\title{
Oxygen-evolution reaction by nickel/nickel oxide interface in the presence of ferrate(VI)
}

\author{
Mohammad Saleh Ali Akbari', Robabeh Bagheri' ${ }^{2}$, Zhenlun Song ${ }^{2}$ \& \\ Mohammad Mahdi Najafpour ${ }^{1,3,4} \bowtie$
}

In this study, we investigate the effect of $\mathrm{K}_{2} \mathrm{FeO}_{4}$, as a new and soluble Fe salt at alkaline conditions, on oxygen-evolution reaction (OER) of $\mathrm{Ni}$ oxide. Both oxidation and reduction peaks for $\mathrm{Ni}$ in the presence and absence of Fe are linearly changed by (scan rate) $)^{1 / 2}$. Immediately after the interaction of $\left[\mathrm{FeO}_{4}\right]^{2-}$ with the surface of the electrode, a significant increase in OER is observed. This could be indicative of the fact that either the $\left[\mathrm{FeO}_{4}\right]^{2-}$ on the surface of $\mathrm{Ni}$ oxide is directly involved in $\mathrm{OER}$, or, it is important to activate $\mathrm{Ni}$ oxide toward OER. Due to the change in the $\mathrm{Ni}(\mathrm{II}) /(\mathrm{III})$ peak, it is hypothesized that Fe impurity in $\mathrm{KOH}$ or electrochemical cell has different effects at the potential range. At low potential, $\left[\mathrm{FeO}_{4}\right]^{2-}$ is reduced on the surface of the electrode, and thus, is significantly adsorbed on the electrode. Finally, oxygenevolution measurements of $\mathrm{K}_{2} \mathrm{FeO}_{4}$ and $\mathrm{Ni}_{2} \mathrm{O}_{3}$ are investigated under chemical conditions. $\mathrm{K}_{2} \mathrm{FeO}_{4}$ is not stable in the presence of $\mathrm{Ni}(\mathrm{II})$ oxide, and $\mathrm{OER}$ is observed in a $\mathrm{KOH}$ solution $(\mathrm{pH} \approx 13$ ).

Rapid depletion of fossil fuels and environmental problems have forced humans to find clean and sustainable energy sources ${ }^{1}$. Water-splitting reaction is a promising strategy for storing energy ${ }^{2}$. One limitation of water-splitting reaction is $\mathrm{OER}^{3}$. Thus, finding an efficient, stable, low-cost, earth-abundant, and environmentally friendly catalyst for this reaction is a challenging issue $e^{4-8}$.

Thomas A. Edison was the first to recognize the effect of Fe on decreasing the electrochemical capacity of $\mathrm{Ni}$ oxide. Following this finding, evidence from studies pointed to the fact that Fe ions significantly decrease the onset of OER of $\mathrm{Ni}$ oxide $\mathrm{e}^{9,10}$. Ni oxides are poor catalysts for OER, but the incorporation of Fe into Ni oxide forms an efficient catalyst for $\mathrm{OER}^{9-12}$. Corrigan (1987) studied the effects of $\mathrm{Fe}(0.01 \% \mathrm{Fe}$ present) on OER by $\mathrm{Ni}$ oxide $^{11}$. The findings suggested that the incorporation of Fe ions in Ni oxide causes the Tafel slopes to drop from about $70 \mathrm{mV} /$ decade to about $25 \mathrm{mV} /$ decade $^{11}$.

Boettcher's group extensively investigated Fe-Ni oxide in OER ${ }^{12}$. The research group found that the increased conductivity by $\mathrm{Fe}$ ions in $\mathrm{Ni}$ oxide structure is not enough to explain the increased activity in Ni oxide toward OER $^{12}$. They suggested that Fe affects the electronic structure of Ni oxide by inducing partial-charge transfer ${ }^{12}$. Their work also disproved the long-held view that $\beta-\mathrm{NiOOH}$ is intrinsically more active than $\gamma-\mathrm{NiOOH}$, which is related to the increase in OER through the incorporation of $\mathrm{Fe}$ ions in $\mathrm{Ni}_{\text {oxide }}{ }^{12}$.

The Pourbaix diagram shows that $\mathrm{Fe}(\mathrm{VI})$, and $\mathrm{Ni}(\mathrm{IV})$ species could be formed under OER conditions ${ }^{13,14}$. Therefore, the oxidation states of $\mathrm{Ni}$ and $\mathrm{Fe}$, and the mechanism of OER by Fe-Ni oxide are challenging issues in the field. The role of Fe on Ni oxide during OER has become a source of controversy.

Some experimental methods and DFT calculations of Ni-Fe oxides have shown that OER occurs at Fe-sites embedded in the Ni oxide ${ }^{15}$. Another study confirmed that OER could proceed on Ni(IV) sites ${ }^{16,17}$. Bard's group suggested that $\mathrm{Ni}(\mathrm{IV})$ is a poor active site during OER and that the highly active sites are the dispersed Fe ions in the Ni-oxide matrix ${ }^{18}$.

Using XANES, Dau's group detected Ni(IV) ${ }^{19}$. Jin, Alp, and Stah detected Fe(IV) by the operando Mössbauer spectroscopic studies of a 3:1 Ni:Fe layered hydroxide ${ }^{20}$. However, Fe(IV) ions do not account for the catalytic

\footnotetext{
${ }^{1}$ Department of Chemistry, Institute for Advanced Studies in Basic Sciences (IASBS), Zanjan, 45137-66731, Iran. ${ }^{2}$ Key Laboratory of Marine Materials and Related Technologies, Zhejiang Key Laboratory of Marine Materials and Protective Technologies, Ningbo Institute of Materials Technology and Engineering, Chinese Academy of Sciences, Ningbo, 315201, China. ${ }^{3}$ Center of Climate Change and Global Warming, Institute for Advanced Studies in Basic Sciences (IASBS), Zanjan, 45137-66731, Iran. ${ }^{2}$ Research Center for Basic Sciences \& Modern Technologies (RBST), Institute for Advanced Studies in Basic Sciences (IASBS), Zanjan, 45137-66731, Iran. ${ }^{\circledR}$ e-mail: mmnajafpour@iasbs. ac.ir
} 
activity $^{20}$. In 2018, Chorkendorff's group electrochemically oxidized the nanoparticles of metallic Ni-Fe alloy in an electrolyte containing $\mathrm{H}_{2}{ }^{16} \mathrm{O}$ to form $\mathrm{NiFe}^{16} \mathrm{O}_{x} \mathrm{H}_{y}$; in the next step, they added $\mathrm{H}_{2}{ }^{18} \mathrm{O}$ to the electrolyte. No participation of lattice oxygen in $\mathrm{NiFe}^{16} \mathrm{O}_{\mathrm{x}} \mathrm{H}_{\mathrm{y}}$ was observed ${ }^{21,22}$.

Using ${ }^{18} \mathrm{O}$-labeling experiments in combination with in situ Raman spectroscopy, it was found that lattice oxygen is involved in OER by $\mathrm{Ni}$ and $\mathrm{Ni} / \mathrm{Co} \mathrm{LDHs}$, but not when $\mathrm{Ni}-\mathrm{Fe}$ and $\mathrm{Ni} / \mathrm{Co} / \mathrm{Fe} \mathrm{LDH}$ are involved ${ }^{23}$.

The roles of dissolved Ni species in OER was reported by He's group ${ }^{24}$. Other elements do not considerably affect OER of Ni oxide. However, some groups reported that Fe ions in electrolyte react with the surface of Co, $\mathrm{Ni}$, $\mathrm{Cu}, \mathrm{Ag}, \mathrm{Au}$, but not with Ti electrodes, and form the active sites for OER ${ }^{12,14}$.

It was reported that nickel(II) and cobalt(II) have a significant effect on the decomposition of $\left[\mathrm{FeO}_{4}\right]^{2-25}$

Herein, OER by $\mathrm{Ni}$ oxide in the presence of $\left[\mathrm{FeO}_{4}\right]^{2-}$ is reported. In addition to the electrochemical experiments, OER by $\left[\mathrm{FeO}_{4}\right]^{2-}$ and $\mathrm{Ni}_{2} \mathrm{O}_{3}$ was also investigated, and the results are reported. These findings showed that in addition to the hypothesis of the effect of Fe on the oxygen-evolving activity of $\mathrm{Ni}$ oxide, the effect of $\mathrm{Ni}$ ions on the oxygen-evolving activity of high-valent Fe active sites should also be investigated.

\section{Results}

In this study, $\left[\mathrm{FeO}_{4}\right]^{2-}$ was used as an Fe salt, and its effect on $\mathrm{Ni}$ oxide was investigated during OER. Using $\left[\mathrm{FeO}_{4}\right]^{2-}$ as an Fe salt has some advantages:

(i) It is a new Fe salt for investigating the effect of Fe on OER by nickel oxide.

(ii) In contrast to many Fe salts, $\left[\mathrm{FeO}_{4}\right]^{2-}$ is soluble under alkaline conditions. Thus, it could be easily added to nickel oxide under the potential to allow direct observation of the effect of Fe on OER of nickel oxide.

(iii) In contrast to $\mathrm{Fe}(\mathrm{III}),\left[\mathrm{FeO}_{4}\right]^{2-}$ has a negative charge, and its migration toward the anode is easier than the migration of $\mathrm{Fe}\left(\mathrm{OH}_{2}\right)_{6}{ }^{3+}$ with the positive charge.

(iv) In the absence of the potential or a reductant, it has relatively good stability at high $\mathrm{pH}(>12)$.

(v) It shows a sharp peak in the visible spectra (violet color), and thus, its concentration could be detectable. (xvi) $\left[\mathrm{FeO}_{4}\right]^{2-}$ has been proposed as an intermediate in $\mathrm{OER}^{26}$.

(xvii) By using $\left[\mathrm{FeO}_{4}\right]^{2-}$, relatively homogeneous layers of Fe oxide on the Ni foam is obtained, which is a promising synthetic method.

The sodium or potassium, but not barium ferrate (VI), $\left[\mathrm{FeO}_{4}\right]^{2-}$, is soluble in water ${ }^{27}$. $\left[\mathrm{FeO}_{4}\right]^{2-}$, a tetrahedral ion with violet color, has a strong oxidizing activity and is relatively stable at high $\mathrm{pH}$. $\left[\mathrm{FeO}_{4}\right]^{2-}$ salt is produced by the oxidation of $\mathrm{Fe}$ in an aqueous medium under the alkaline conditions in the presence of $\mathrm{Cl}_{2}$, and by heating Fe filings in the presence of potassium nitrate. $\left[\mathrm{FeO}_{4}\right]^{2-}$ has a reduction potential of $+2.2 \mathrm{~V}$ to $+0.7 \mathrm{~V}$ versus $\mathrm{NHE}$ at $\mathrm{pH} 0$ and 14, respectively ${ }^{27}$.

In this study, a nickel foam was used as the source of nickel oxide. First, a Ni foam was placed under oxidation conditions at $10.0 \mathrm{~V}$ for 20 minutes in a two-electrode setup in a $\mathrm{KOH}$ solution $(\mathrm{pH} \approx 13)$. Then it was used for the electrochemical investigation. Because soluble nickel compounds may affect the electrochemistry of the electrode ${ }^{24}$, no nickel oxide was used to purify ${ }^{12}$ the electrolyte in our experiments.

LSV of the Ni foam in $\mathrm{KOH}(\mathrm{pH} \approx 13)$ showed that before adding $\left[\mathrm{FeO}_{4}\right]^{2-}$, the onset of OER is observed at $1.52 \mathrm{~V}$ (in the paper, all potentials are reported vs. RHE) (Fig. 1a). Ni(II)/(III) oxidation is also revealed at $1.43 \mathrm{~V}$ (Eq. 1):

$$
\mathrm{Ni}(\mathrm{OH})_{2}+\mathrm{OH}^{-} \rightarrow \mathrm{NiOOH}+\mathrm{e}^{-}+\mathrm{H}_{2} \mathrm{O}
$$

The consecutive CVs are interesting in that they show the effect of the impurity of Fe and the addition of $\left[\mathrm{FeO}_{4}\right]^{2-}$. As shown in Fig. 1a, in the absence of the $\left[\mathrm{FeO}_{4}\right]^{2-}$ and the presence of the impurity of Fe impurity in $\mathrm{KOH}$ or electrochemical cell, an increase in OER (orange arrow) is observed during the consecutive CVs. The Ni oxidation peak shifts from 1.43 to $1.46 \mathrm{~V}$ during the consecutive CVs (Fig. 1a). After adding the Fe salt (the final concentration of Fe salt was $0.25 \mathrm{mM}$. If another concentration of Fe salt was used, it was written in the related captions), a significant change is observed in OER (pink arrow), and the Ni oxidation peak is observed at $1.50 \mathrm{~V}$ (Fig. 1a).

The same CV is observed for a pure metallic Ni foil (99.99\% purity; Fig. 1b). For a pure metallic Ni foil, the first no peak is observed for $\mathrm{Ni}$ (II)/(III) oxidation, since no pre-treatment at high potential was performed for the foil. However, after a few consecutive CVs, the peak at $1.46 \mathrm{~V}$ was observed, which shows a shift to the higher potential at $100^{\text {th }} \mathrm{CV}(1.48 \mathrm{~V})$ (Fig. $1 \mathrm{~b}$ ). To find the effect of the amounts of Ni oxide on OER, a Ni foam without any anodization at $10.0 \mathrm{~V}$ was also investigated, which showed similar characteristics to the anodized Ni foil (Fig. S1).

After 100 consecutive CVs at a scan rate of $25 \mathrm{mV} / \mathrm{s}$ in the absence of adding Fe ions, the onset of OER and the peak are observed at 1.48 and $1.47 \mathrm{~V}$ by LSV, respectively (Fig. 1c). The changes correspond to the incorporation of Fe impurity in $\mathrm{KOH}$ or electrochemical cell to Ni oxide. After adding Fe salt, the onset of OER was observed at $1.39 \mathrm{~V}$. The related peak to $\mathrm{Ni}$ (II)/(III) oxidation is observed at $1.50 \mathrm{~V}$. The peak shape is significantly changed in the presence of adding Fe ions.

SWV indicated the peaks for $\mathrm{Ni}$ (II)/(III) oxidation before and after adding the Fe salt. Before adding the Fe salt in $\mathrm{KOH}(\mathrm{pH} \approx 13)$, a peak at $1.37 \mathrm{~V}$ was observed (Fig. 1d), which corresponded to $\mathrm{Ni}(\mathrm{II}) / \mathrm{Ni}$ (III) oxidation; after 50 consecutive CVs, this peak shifted to $1.39 \mathrm{~V}$, which was related to the effect of impurity in $\mathrm{KOH}$ or electrochemical cell. After adding Fe, the peak was observed at $1.43 \mathrm{~V}$ (Fig. 1d). The multi-step amperometry at 1.36-2.16 V before adding the Fe salt (blue) and after adding the Fe salt (red) is shown in Fig. 1e. Before adding the Fe salt at $1.96 \mathrm{~V}, 5 \mathrm{~mA}$ increase in OER was observed, which was related to impurity in KOH or electrochemical cell (pink line). 
a

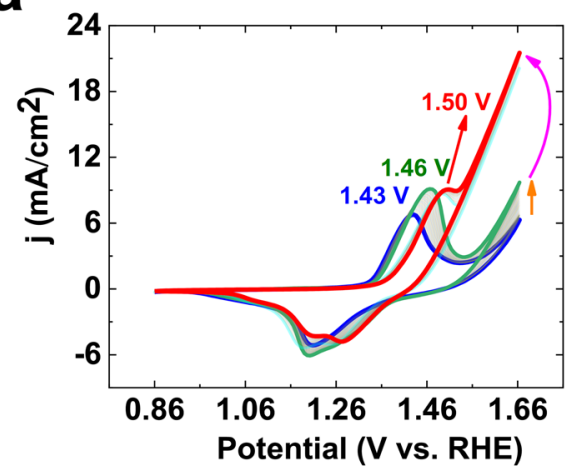

C

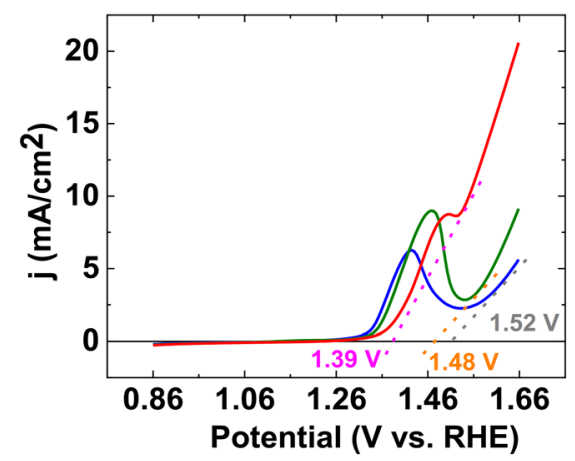

b

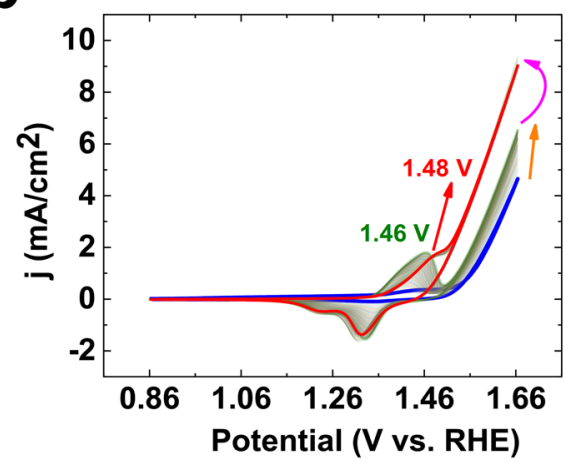

d

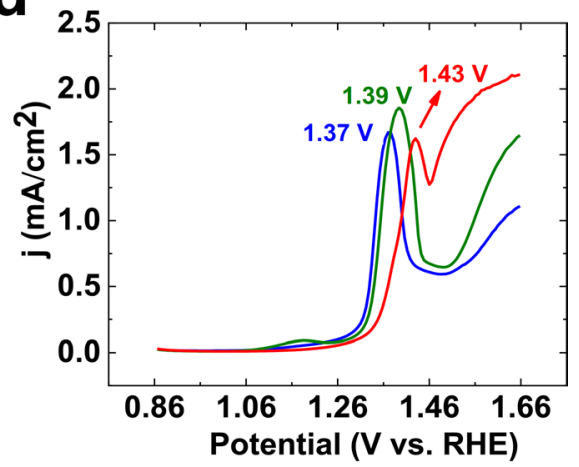

e

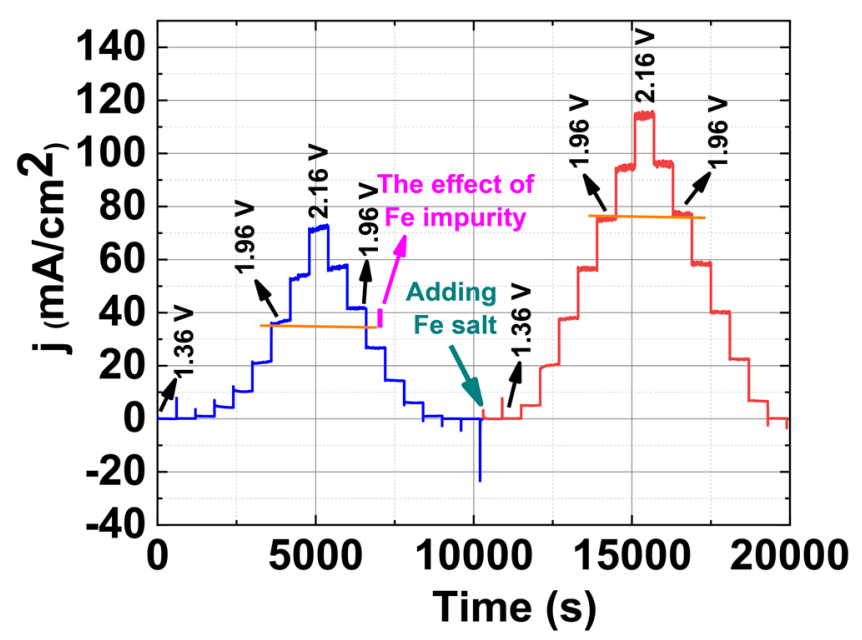

Figure 1. 150 consecutive CVs of the $\mathrm{Ni}$ foam (a) or Ni foil ( $99.99 \%$ purity) (b) (scan rate: $25 \mathrm{mV} / \mathrm{s}$ ) in the absence and presence of the Fe salt. After the $100^{\text {th }} \mathrm{CV}$, the Fe salt was added to the electrolyte. The $2^{\text {nd }} \mathrm{CV}$ is shown in blue. The $150^{\text {th }} \mathrm{CV}$ is shown in red. The orange arrow indicates an increase in OER in the presence of Fe impurity in $\mathrm{KOH}$ or electrochemical cell. The pink arrow indicates an increase in OER in the presence of the Fe salt. LSVs after $1^{\text {st }}$ and $100^{\text {th }}$ CVs for Ni foil before adding the Fe salt are shown in blue and green, respectively. LSV of Ni foil after adding the Fe salt (red). The numbers show the onsets of OER for LSVs (c). SWV of Ni foil before adding the Fe salt (blue). SWV of Ni foil after the $100 \mathrm{CV}$ (green) (d). SWV of Ni foil after adding the Fe salt and CV (red). The numbers show the peaks for Ni oxidation (d). Multi-step amperometry at $1.36-2.16 \mathrm{~V}$ before adding the Fe salt (blue) and after adding the Fe salt (red). The green arrow indicates the time of the addition of the $\mathrm{Fe}$ salt $(\mathbf{e})$. The small orange line indicates the effect of $\mathrm{Fe}$ impurity on the current density at $1.96 \mathrm{~V} . \mathrm{KOH}(\mathrm{pH} \approx 13)$ was used for all experiments.

In the next step, the effect of different scan rates on OER, Ni oxidation and reduction peaks were investigated (Fig. 2). In all recorded scan rates, the Ni oxidation/reduction peaks in the absence and presence of Fe were observed. Both oxidation and reduction peaks for $\mathrm{Ni}$ in the presence and absence of Fe shifted linearly by (scan 
a

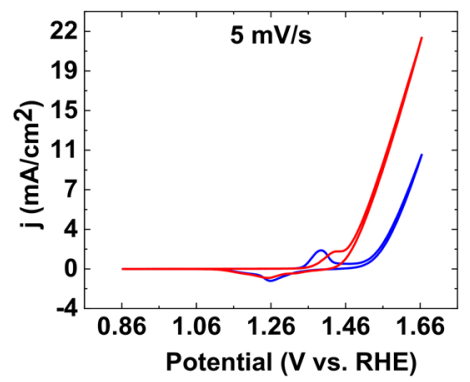

d

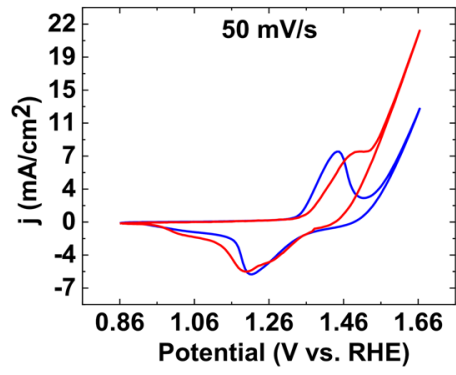

g

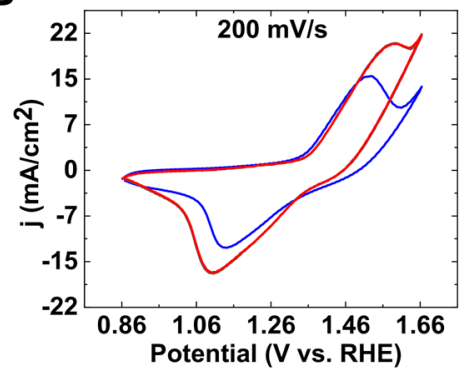

b

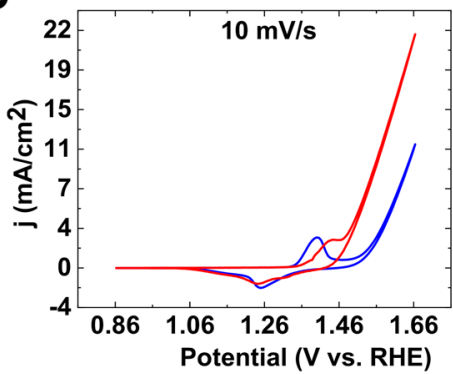

e

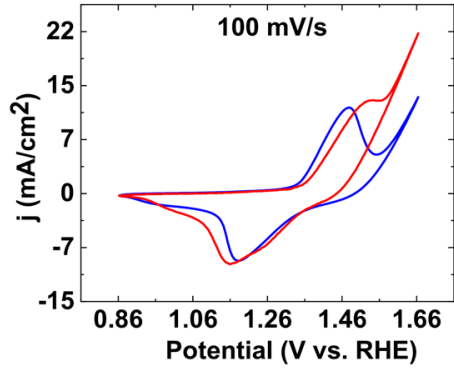

h

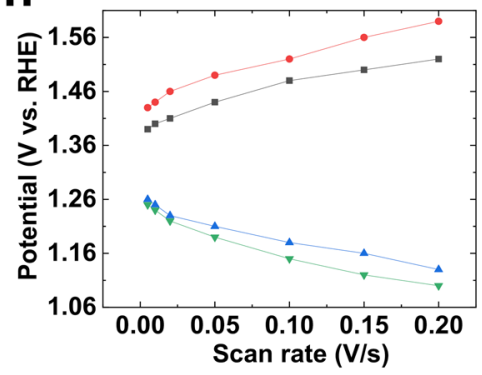

C

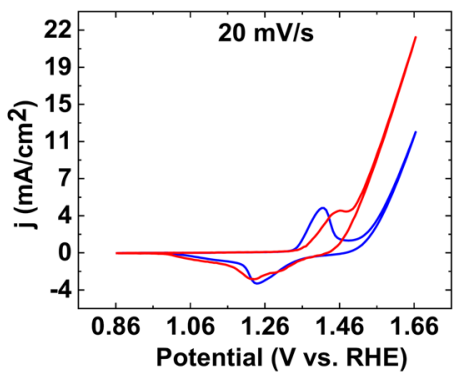

f

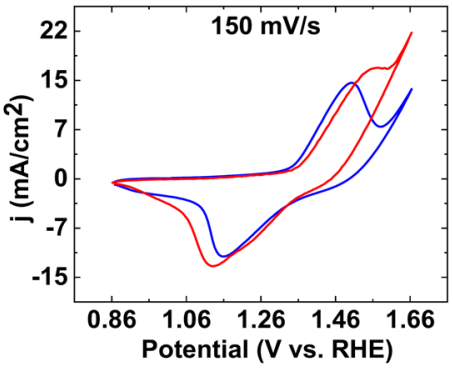

i

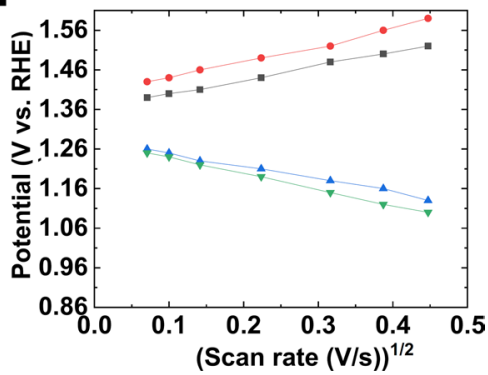

Figure 2. CVs of the Ni foam at different scan rates in the absence (blue) and presence of the Fe salt (red) (a-g). Potential vs. (scan rate) $(\mathbf{h})$ and potential vs. (scan rate) ${ }^{1 / 2}$ (i) plots for Ni foam in the absence and presence of the $\mathrm{Fe}$ salt. $\mathrm{KOH}(\mathrm{pH} \approx 13)$ was used for all experiments. For $(\mathbf{h}, \mathbf{i})$, red and black indicate the $\mathrm{Ni}(\mathrm{II}) /(\mathrm{III})$ oxidation peaks in the presence and absence of the Fe salt, respectively; green and blue indicate the $\mathrm{Ni}(\mathrm{III}) /(\mathrm{II})$ reduction peaks in the presence and absence of the Fe salt, respectively.

rate $)^{1 / 2}$ (Fig. 2i), which showed freely diffusing species were important to form these peaks. The oxidation peaks shifted to higher potentials, and reduction peaks shifted to lower potential in the presence of Fe ions.

In the next step, the Fe salt was added to the electrolyte in the form of solid powder, and CVs were recorded (Fig. 3a,b). The salt slowly diffused toward the electrode, and an improvement in OER was observed. Interestingly, immediately after the interaction of the Fe salt with the electrode, a significant increase in OER was observed (see the video, SI). This could show that Fe ions on the surface of Ni oxide were directly involved in OER or were important to the activation of Ni oxide toward OERs. After 80 consecutive CVs, a constant current was observed for OER (Fig. 3a,b), which showed that a few Fe sites were enough to optimize OER by Ni oxide.

The effect of the step by step addition of Fe ions to Ni oxide was studied. To inhibit the effect of the Fe salt on the cathode, the experiment was performed in a two-cell setup. As shown in Fig. 3c, at $1.46 \mathrm{~V}$ in $\mathrm{KOH}(\mathrm{pH} \approx 13)$, adding the Fe salt in the first step had a significant effect. However, adding more Fe salt had less effect on OER. If $\mathrm{Ni}$ sites are the active sites for OER, a decrease in OER may be observed after significantly covering the Ni sites by Fe ions. Surprisingly, however after adding more Fe salt, OER was increased. Thus, it is hypothesized that Fe sites could be active sites for OER.

The effect of large amounts of the Fe salt $(12.6 \mathrm{mM})$ on OER of the Ni foam was investigated (Fig. $3 \mathrm{~d}, \mathrm{e})$. Adding large amounts of Fe salt had no significant effect on OER compared to a small amount of Fe salt. After 100 consecutive CVs, a constant current was observed for the electrode in the presence of the Fe salt (Fig. 3d,e).

An interesting idea is to analyze the effect of the Fe salt on the CV of Ni oxide. The subtraction (Fig. 4a, orange plot) of the CV in the absence of the Fe salt and the CV in the presence of the Fe salt is shown in Fig. $4 \mathrm{~b}$. It seems that the redox property of $\mathrm{Ni}$ (III) was used by Fe to increase in OER (B area in Fig. 4b). In other words, it is hypothesized that Ni sites, which remain at high oxidation states before the addition of Fe, are pushed to be discharged by Fe ions toward OER in the presence of Fe (B area in Fig. 4b). 
a

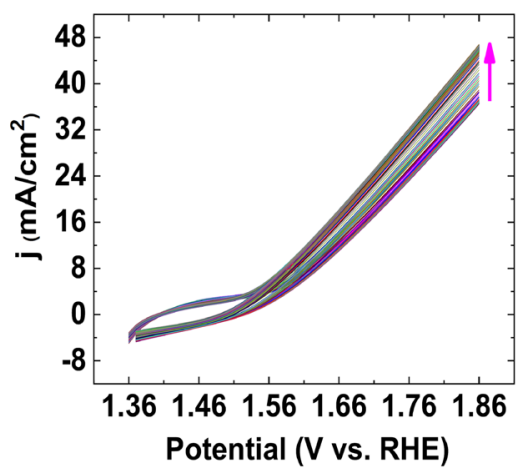

C

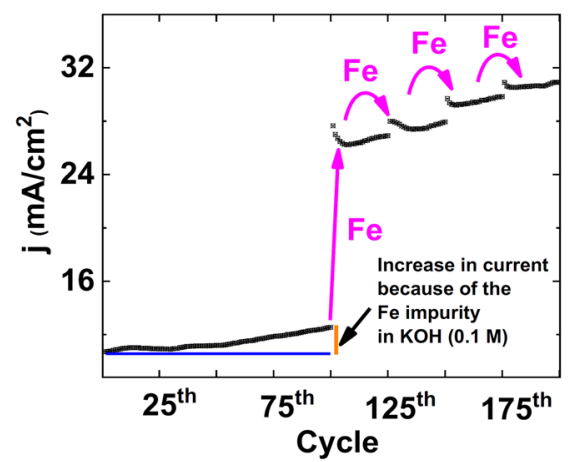

b

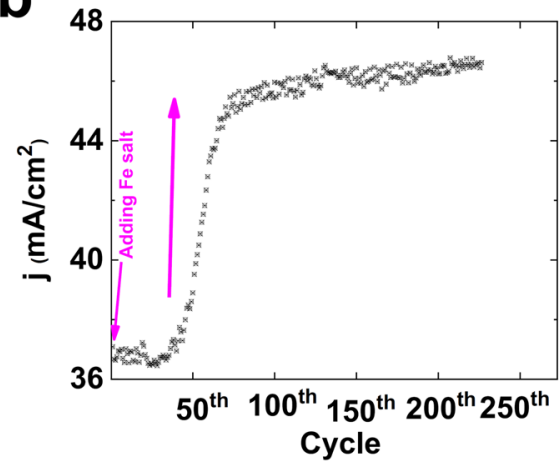

d

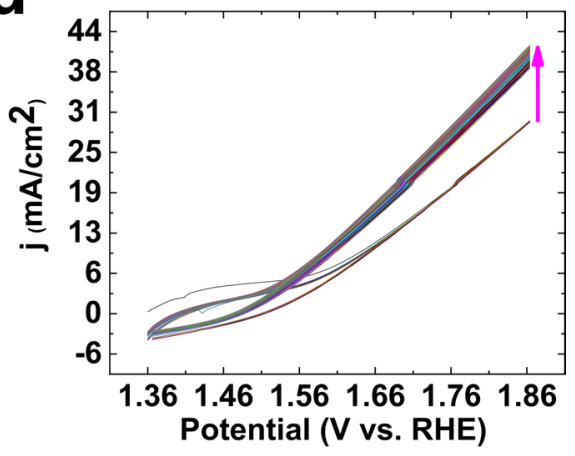

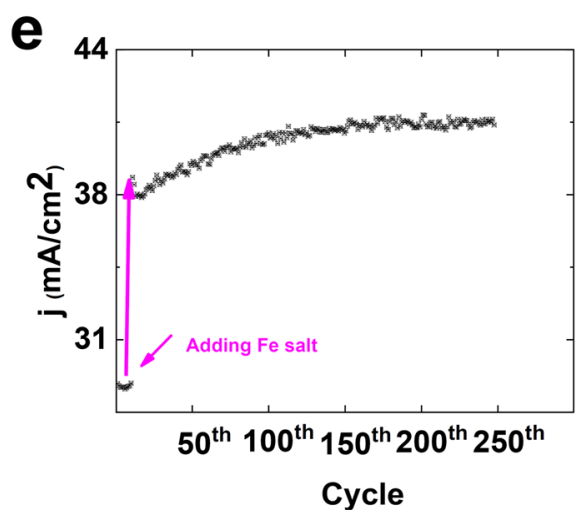

Figure 3. The effect of the Fe salt in the form of solid powder on CVs (scan rate: $25 \mathrm{mV} / \mathrm{s}$ ) of Ni foam (a). The current density at $1.86 \mathrm{~V}$ for the consecutive CVs in the image $\mathbf{a}(\mathbf{b})$. The effect of continuous addition of Fe salt (final concentrations in each step: $0.25,0.50,0.75$ and $1.0 \mathrm{mM}$ ) on the current density at $1.86 \mathrm{~V}$ for the consecutive $\mathrm{CVs}(\mathrm{KOH}, \mathrm{pH} \approx 13)$ of $\mathrm{Ni}$ foam $(\mathbf{c})$. The effect of large amounts of the Fe salt (final concentration: $12.6 \mathrm{mM}$ ) on $\mathrm{CVs}$ of $\mathrm{Ni}$ foam (scan rate: $25 \mathrm{mV} / \mathrm{s}, \mathrm{KOH}, \mathrm{pH} \approx 13)(\mathbf{d})$. The current density at $1.86 \mathrm{~V}$ for the consecutive CVs in the image $\mathbf{d}(\mathbf{e})$.

Graphite electrode has no synergistic interaction with the Fe salt and the subtraction of the CV for graphite (green plot) in the absence and presence of Fe shows the effect of Fe on the electrode toward OER (Fig. 5c). It is interesting that the green and orange plots are comparable (Fig. $4 \mathrm{~b}, \mathrm{c}$ ), if we withdraw the $\mathrm{Ni}$ (II)/(III) oxidation/ reduction peaks. The orange plot is just bigger, and its onset of OER is observed at a low overpotential. The similarity between orange and green plots could show that in Fe-Ni oxide, similar to the case where Fe is on graphite, the Fe ions are active sites for OER.

If we subtract the pure effect of Fe (green plot) from the orange plot in Fig. 4d, the synergistic effect of Fe on nickel could be calculated (black plot). As shown in Fig. 4d, it is hypothesized that $\mathrm{Ni}(\mathrm{II}) /(\mathrm{III})$ oxidation occurs before OER in pure Ni oxide and the absence of Fe. However, after adding the Fe salt, Ni(II)/(III) oxidation occurs in the same potential as the onset of OER. The onset of OER is observed at $100 \mathrm{mV}$ lower by Fe-Ni oxide than Fe ions on graphite (Fig. 5d).

In the next study, the effect of the potential range on the effect of $\mathrm{Fe}$ on OER by Ni oxide was investigated (Fig. 5). Before adding the Fe salt at (1.56-1.86 V) range (Fig. 5a), the consecutive CVs showed no clear increase in OER. After adding the Fe salt at this range (Fig. 5a), an increase in OER (1.2 times) was observed, which was constant during the time of the reaction. 
a

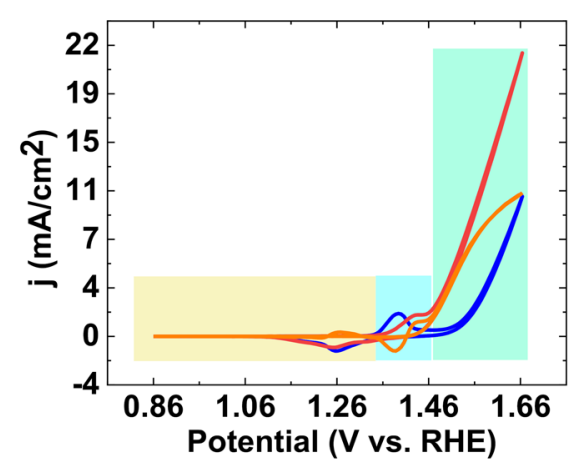

C

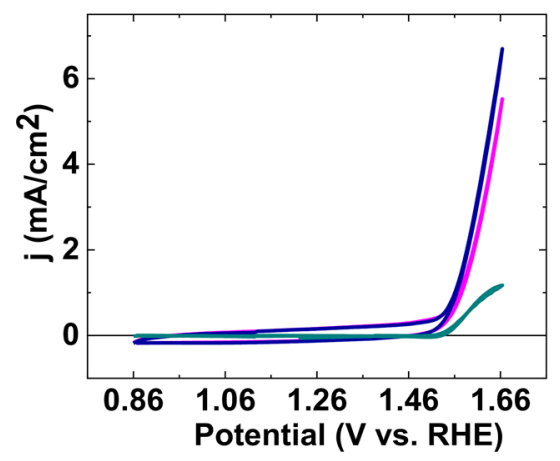

b

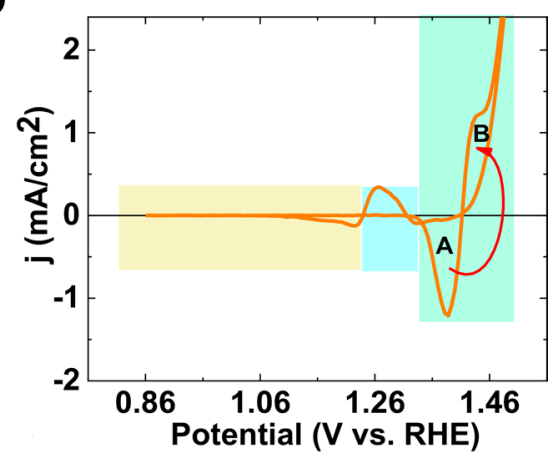

d

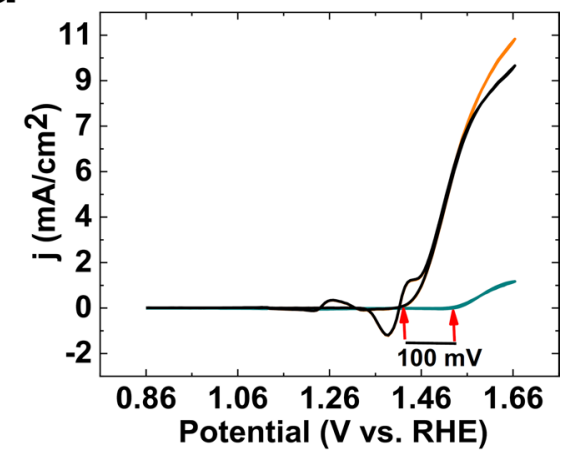

Figure 4. The subtraction (orange plot) of CV in the absence (blue CV) and presence (red CV) of the Fe salt $(\mathbf{a}, \mathbf{b})$. In the presence of the Fe salt $(0.25 \mathrm{mM})$, the subtraction shows that the Fe salt decreases the capacitance of $\mathrm{Ni}$ oxide at 1.36-1.46 $\mathrm{V}$ range (A area). On the other hand, it seems that these charges are used by Fe to increase OER (B area). The subtraction (green plot) of CV in the absence (pink CV) and presence (blue CV) of the Fe salt in the presence of graphite $(\mathbf{c})$. The subtraction of orange plot in (b) of green plot in $\mathbf{c}(\mathbf{d})$. All scan rates were $25 \mathrm{mV} / \mathrm{s}$ and $\mathrm{KOH}(\mathrm{pH} \approx 13)$.

Before adding the Fe salt at (1.36-1.86 V) range, consecutive CVs showed an increase in OER (two times) at the $150^{\text {th }} \mathrm{CV}$ (Fig. 5b). After adding the Fe salt at this range, a few increases (1.1 times) in OER was observed, which was constant during the time of reaction (Fig. 5b).

Before adding the Fe salt at $(0.86-1.86 \mathrm{~V})$ range (Fig. $5 \mathrm{c}$ ), the consecutive CVs showed an increase in OER (1.5 times) at the $150^{\text {th }} \mathrm{CV}$. After adding the Fe salt at this range, a few increases ( 1.3 times) in OER was observed, which was constant during the time of reaction (Fig. $5 \mathrm{c}$ ).

Before adding the Fe salt at $(-0.14-1.86 \mathrm{~V})$ range (Fig. 5d), the consecutive CVs showed an increase in OER ( 1.75 times) at the $150^{\text {th }} \mathrm{CV}$. After adding the Fe salt at this range, a few increases (1.15 times) in OER was observed, which was constant during the time of reaction (Fig. 5d).

Before adding the Fe salt, it seems that the activation factor needed a potential of less than $1.56 \mathrm{~V}$. Given the change in the $\mathrm{Ni}(\mathrm{II}) /(\mathrm{III})$ peak, it is hypothesized that impurity in $\mathrm{KOH}$ or electrochemical cell is the active factor. At a low potential, Fe ions are reduced on the surface of the electrode, and thus, are significantly adsorbed on the electrode. Thus, after the $150^{\text {th }} \mathrm{CV}$, a high activity for Ni oxide is observed. After adding Fe impurity on the surface of the electrode at a low potential, an Fe saturation occurs for Fe ion on the surface of the electrode, and the current remains constant. The related peak to $\mathrm{Fe}(\mathrm{II}) / \mathrm{Fe}(\mathrm{III})$ oxidation/reduction in Ni-Fe oxide is displayed at $0.36 \mathrm{~V} /-0.06 \mathrm{~V}$, respectively (Eq. 2):

$$
\mathrm{Fe}(\mathrm{OH})_{2}+\mathrm{OH}^{-} \rightarrow \mathrm{FeOOH}+\mathrm{e}^{-}+\mathrm{H}_{2} \mathrm{O}
$$

SEM images show that a fresh $\mathrm{Ni}$ foam has a cellular structure with high porosity and a large volume fraction of pores (Figs. 6a,b, S2). After operating the Ni foam at $10.0 \mathrm{~V}$, a few corrosive points (ca. $10 \mathrm{~nm}$ ) were observed on the surface of the cellular structure of the foam (Figs. 6c,d, Fig. S3 and S4). Small particles (20-40 nm) were also observed on the surface of the $\mathrm{Ni}$ foam (Fig. 6c,d). Under the operation at $10.0 \mathrm{~V}$, no detectable iron was observed by EDX-SEM on the surface of the foam.

$\mathrm{X}$-ray photoelectron spectroscopy (XPS) was used to characterize the operated foam at $10.0 \mathrm{~V}$. Ni $2 \mathrm{p}$ peak showed significant split spin-orbit components $(17.8 \mathrm{eV})$. Ni $2 \mathrm{p} 3 / 2$ spectrum of the operated foam at $10.0 \mathrm{~V}$ indicated a peak at $855.3 \mathrm{eV}$, which is related to Ni hydroxide (Fig. S5a) ${ }^{28}$. Ni $2 \mathrm{p} 1 / 2$ was also observed at $873 \mathrm{eV}$. Satellite features for Ni 2p3/2 and Ni 2p1/2 were displayed at 861 and $879 \mathrm{eV}$, respectively.

In addition, $\mathrm{O} 1 \mathrm{~s}$ component after the operation showed a peak at 531.1 attributed to oxygen in Ni hydroxide, $\mathrm{OH}$, and $\mathrm{OH}_{2}$ groups on the surface of the electrode (Fig. S5b) ${ }^{29}$. 
a

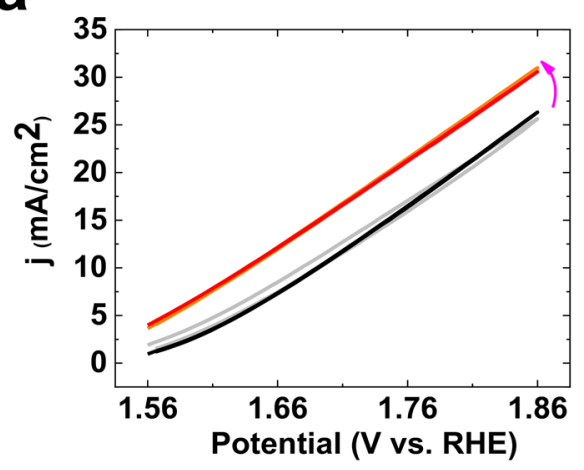

C

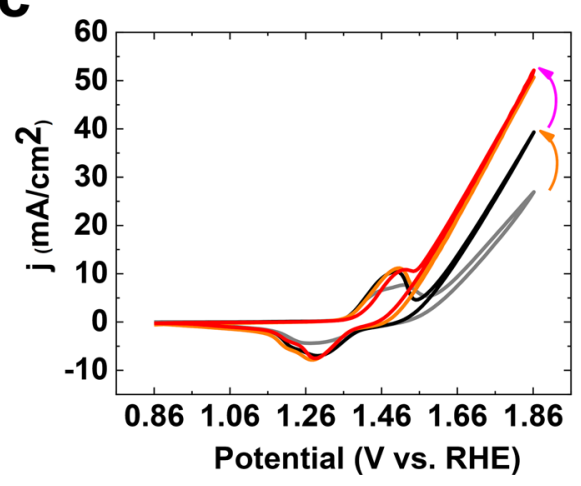

b

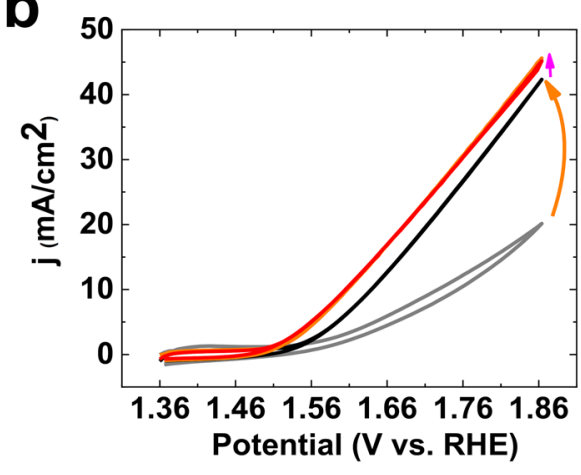

d

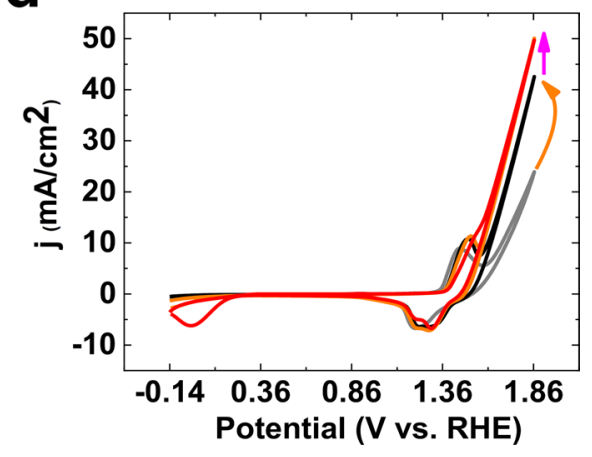

Figure 5. $\mathrm{CV}$ of the $\mathrm{Ni}$ foam at different potential ranges in the absence (grey), after the $50^{\text {th }} \mathrm{CV}$ (black) and the presence of the Fe salt $\left(1^{\text {st }} \mathrm{CV}\right.$ : orange; $50^{\text {th }} \mathrm{CV}$ : red) (scan rate: $\left.25 \mathrm{mV} ; \mathrm{KOH}(\mathrm{pH} \approx 13)\right)(\mathbf{a}-\mathbf{d})$.

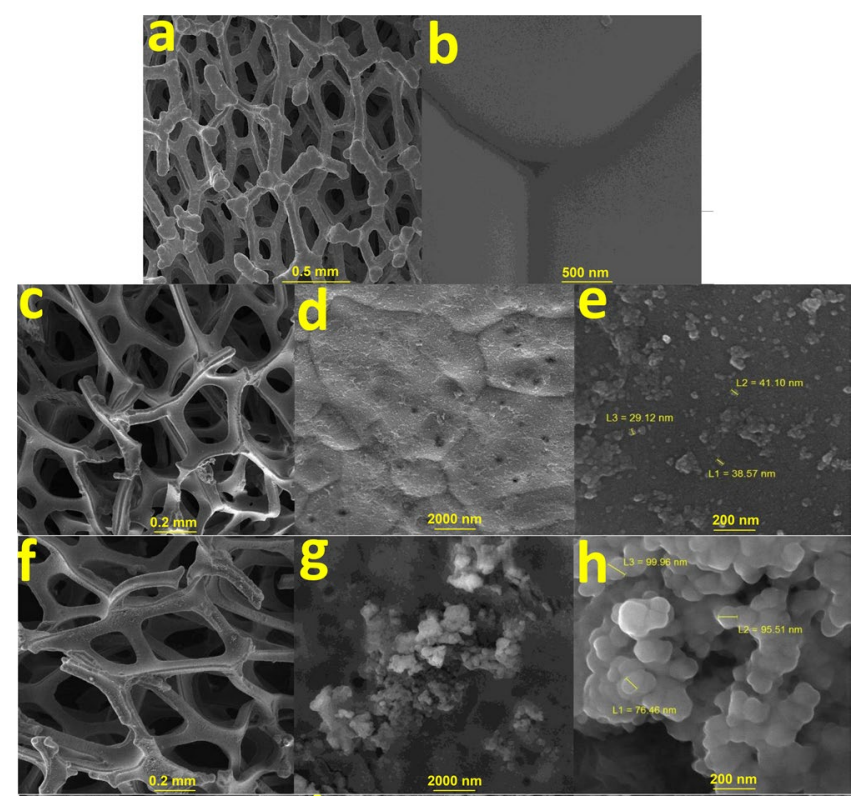

Figure 6. SEM images of the fresh Ni foam with different magnifications (a,b). SEM images of the operated $\mathrm{Ni}$ foam at $10.0 \mathrm{~V}$ with different magnifications $(\mathbf{c}-\mathbf{e})$. SEM images of the anodic Ni foam in the presence of the Fe salt with different magnifications $(\mathbf{f}-\mathbf{h})$. Amperometry at $1.46 \mathrm{~V}$ in $\mathrm{KOH}(\mathrm{pH} \approx 13)$ in a two-compartment electrochemical cell for 2 hours.

High-resolution transmission electron microscopy (HRTEM) images of the mechanically separated solid on the surface of the operated electrode at $10.0 \mathrm{~V}$ showed crystalline areas (ca. 5-10 nm) (Fig. 7). The HRTEM images also indicated a crystal lattice spacing of $0.21-0.23 \mathrm{~nm}$, corresponding to the (101) plane of Ni(II) hydroxide (ref.: 00,001). (111) plane was also observed in the XRD pattern (Fig. S6). 

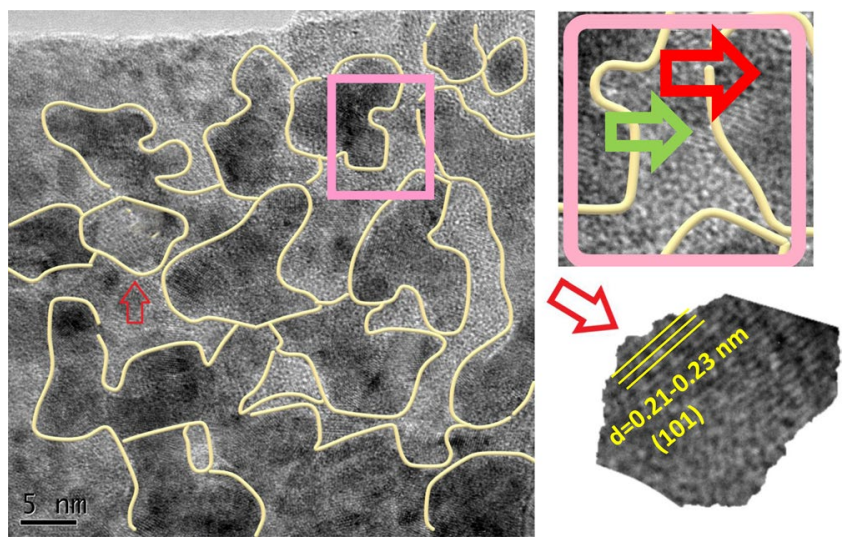

Figure 7. (HR)TEM images of the mechanically separated solid of the operated Ni foam at $10.0 \mathrm{~V}$ with different magnifications. The crystalline areas are showed in yellow boundaries. Red and green arrows show crystalline and amorphous areas, respectively. The HRTEM image indicates a crystal lattice spacing of $0.21-0.23 \mathrm{~nm}$, corresponding to the (101) plane of $\mathrm{Ni}(\mathrm{II})$ hydroxide (ref.: 00-001-1047).

SEM images of the foam as an anode electrode after amperometry at $1.46 \mathrm{~V}$ in $\mathrm{KOH}(\mathrm{pH} \approx 13)$ in a two-compartment electrochemical cell for 2 hours, showed nanoparticles (ca. 70-100 nm) (Figs. 6f-h, S7 and S8). The ratio of ions on the surface of nickel foam in Ni:Fe is 4.7:1.0. Thus, relatively large amounts of Fe are on the surface of the electrode.

XRD showed no patterns related to Fe compound on the surface of the Ni foam after amperometry at $1.46 \mathrm{~V}$ in $\mathrm{KOH}(\mathrm{pH} \approx 13)$ in a two-compartment electrochemical cell for 2 hours (Fig. S9). However, the patterns for the separated iron compounds indicated $\mathrm{Fe}(\mathrm{OH})_{3}$ (Fig. S10) (Ref. code: 00-022-0346; crystal system: Cubic; a $(\AA): 8.3700 ; \mathrm{b}(\AA): 8.3700 ; \mathrm{c}(\AA): 8.3700 ; \alpha\left({ }^{\circ}\right): 90.0000 ; \beta\left({ }^{\circ}\right): 90.0000 ; \gamma\left({ }^{\circ}\right): 90.0000$; volume of cell: 586.38$)$ and FeOOH (Ref. code: 01-076-2301; crystal system: Orthorhombic; a $(\AA)$ : 3.8700; b $(\AA)$ : 12.4000; c $(\AA)$ : 3.0600; $\alpha$ $\left({ }^{\circ}\right)$ : $90.0000 ; \beta\left({ }^{\circ}\right): 90.0000 ; \gamma\left({ }^{\circ}\right): 90.0000$; volume of cell: $\left.586.38 \AA^{3}\right)$. Only a trace amount of Fe could significantly activate $\mathrm{Ni}$ oxide for OER (Fig. 1). Thus, it is concluded that the separated phases such as $\mathrm{Fe}(\mathrm{OH})_{3}$ and $\mathrm{FeOOH}$ are not necessary for oxidizing water.

Oxygen-evolving catalysts are usually powders placed onto conductive substrates by binders. These binders decrease the contact between the electrolytes, electrode, and the catalyst and results in a decrease in the electric conductivity. The stability of these electrodes also is low because of the catalyst separation from the electrodes, especially under high current densities and harsh oxygen evolution. Using adding Fe salt to Ni oxide/Ni interface needs no binder and related limitations for the binder.

OER of $\mathrm{K}_{2} \mathrm{FeO}_{4}$ and $\mathrm{Ni}_{2} \mathrm{O}_{3}$-based compounds under chemical conditions. In the next step, OER in the presence of $\mathrm{K}_{2} \mathrm{FeO}_{4}$ and $\mathrm{Ni}_{2} \mathrm{O}_{3}$ compounds are investigated under chemical conditions (Fig. 8). A few important questions in this regard are:

(1) Whether OER of $\mathrm{Ni}_{2} \mathrm{O}_{3}$ is affected by the $\mathrm{Fe}(\mathrm{III})$ salt or not?

(2) If OER of $\mathrm{K}_{2} \mathrm{FeO}_{4}$ is affected by the $\mathrm{Ni}(\mathrm{II})$ salt or not?

(3) If OER occurs in the presence of both $\mathrm{Ni}_{2} \mathrm{O}_{3}$ and $\mathrm{K}_{2} \mathrm{FeO}_{4}$ ?

The answers to these questions are critical for understanding the mechanism of OER by Fe-Ni oxide. After the deaeration of a $\mathrm{KOH}$ solution $(1.0 \mathrm{mM}), \mathrm{Ni}_{2} \mathrm{O}_{3}$ was added, but no clear oxygen evolution was observed (Fig. 8). In addition to this reaction, as shown by the electrochemical method, $\mathrm{Ni}(\mathrm{III})$ oxide in the absence of Fe ions or potential could not oxidize water. It was demonstrated that $\mathrm{Ni}(\mathrm{III})$ in the $\beta$ - $\mathrm{NiOOH}$-like phase has no activity. Though, it was reported that after the oxidation of $\mathrm{Ni}(\mathrm{III})$ to $\mathrm{Ni}(\mathrm{IV})$, the activity toward OER would be observed ${ }^{30}$.

In the next step, after the deaeration of $\mathrm{Ni}_{2} \mathrm{O}_{3}$ in $\mathrm{KOH}(1.0 \mathrm{mM})$, the $\mathrm{Fe}(\mathrm{III})$ ions was added. Again no detectable OER was observed. This shows that $\mathrm{Fe}(\mathrm{III})$ ions cannot activate $\mathrm{Ni}_{2} \mathrm{O}_{3}$ for OER. Regarding the Pourbaix diagram, it is also unlikely that $\mathrm{Ni}_{2} \mathrm{O}_{3}$ could oxidize $\mathrm{Fe}(\mathrm{III})$ ions (Fig. 8).

In contrast to $\mathrm{Ni}_{2} \mathrm{O}_{3}, \mathrm{~K}_{2} \mathrm{FeO}_{4}$ is not stable, and OER is observed in the presence of this compound in a $\mathrm{KOH}$ solution (1.0 mM) (Fig. 8). Adding $\mathrm{Ni}(\mathrm{II})$ ions or nickel hydroxide significantly increased $\mathrm{OER}$ of a $\mathrm{K}_{2} \mathrm{FeO}_{4}$ solution in a $\mathrm{KOH}$ solution $(1.0 \mathrm{mM})$. It displays that OER could occur by the mechanism of activation of $\mathrm{K}_{2} \mathrm{FeO}_{4}$ using Ni ions (Fig. 8c) ${ }^{31}$.

Another mechanism could be the formation of an $\mathrm{Fe}-\mathrm{Ni}$ oxide by incorporation of Fe ions in $\mathrm{Ni}$ oxide. This $\mathrm{Fe}-\mathrm{Ni}$ oxide could be oxidized by $\mathrm{K}_{2} \mathrm{FeO}_{4}$ in the next state and can oxidize water in the next step. To recognize the activation of $\mathrm{K}_{2} \mathrm{FeO}_{4}$ toward OER on the surface of Ni oxide, a saturated $\mathrm{Ni}$ (II) solution was prepared, and the decomposition of $\mathrm{K}_{2} \mathrm{FeO}_{4}$ was investigated in the absence of Ni oxide, but in the presence of trace but soluble $\mathrm{Ni}(\mathrm{II})$. In the presence of $\mathrm{K}_{2} \mathrm{FeO}_{4}$ solution, adding a trace amount of $\mathrm{Ni}(\mathrm{II})$ ions causes no increase in OER. 
a

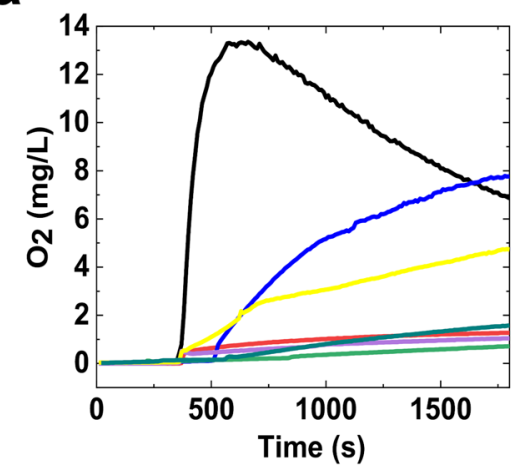

b

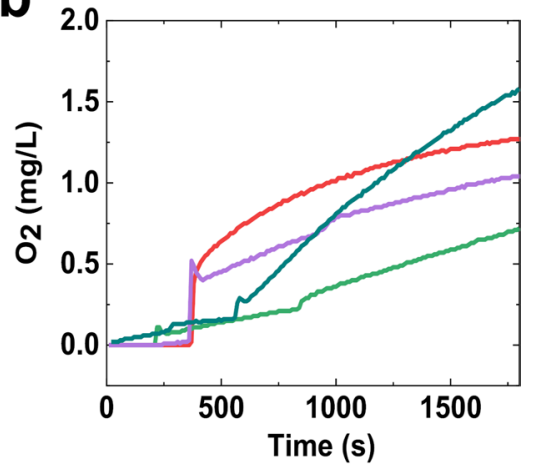

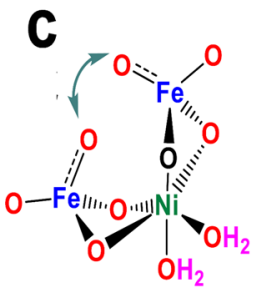

1

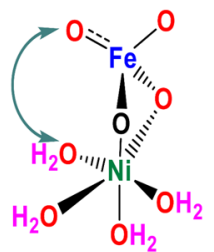

2

Figure 8. Oxygen evolution vs. time plot for $\mathrm{Ni}$ and Fe compounds at $\mathrm{pH}=11$ (Black: $\left[\mathrm{Ni}\left(\mathrm{NO}_{3}\right)_{2}\right]$ : $2.76 \mathrm{mM},\left[\mathrm{K}_{2} \mathrm{FeO}_{4}\right]: 2.83 \mathrm{mM}$; blue: $\left[\mathrm{K}_{2} \mathrm{FeO}_{4}\right]: 2.83 \mathrm{mM}$, [ $\left.\mathrm{Ni}_{\mathrm{x}} \mathrm{Fe}_{\mathrm{y}} \mathrm{OOH}\right]: 36.2 \mathrm{mg}$; yellow: $\left[\mathrm{Ni}_{2} \mathrm{O}_{3}\right]: 100 \mathrm{mg}$, $\left[\mathrm{K}_{2} \mathrm{FeO}_{4}\right]: 2.85 \mathrm{mM}$; pink: $\left[\mathrm{Ni}_{2} \mathrm{O}_{3}\right]: 200 \mathrm{mg} ; \mathrm{Fe}\left(\mathrm{ClO}_{4}\right)_{3} .5 \mathrm{H}_{2} \mathrm{O}: 1.50 \mathrm{mM}, \mathrm{pH}: 11$; dark green: $\left[\mathrm{Ni}_{2} \mathrm{O}_{3}\right]: 10 \mathrm{mg}$; $\left[\mathrm{Fe}\left(\mathrm{ClO}_{4}\right)_{3} .5 \mathrm{H}_{2} \mathrm{O}\right]: 1.50 \mathrm{mM}$; light red: $\left.\mathrm{K}_{2} \mathrm{FeO}_{4}\right]: 2.83 \mathrm{mM}$ and soluble $\mathrm{Ni}(\mathrm{II})$; total volume of solution $45 \mathrm{ml}(\mathbf{a}, \mathbf{b}$ : different scales). Two mechanisms for the activation of $\left[\mathrm{FeO}_{4}\right]^{2-}$ in the presence of $\mathrm{Ni}(\mathrm{II})$ ions (c).

In yet another step, an Fe/Ni hydroxide was synthesized, and OER of the compound was investigated in the presence of $\mathrm{K}_{2} \mathrm{FeO}_{4}$. Compared to soluble $\mathrm{Ni}(\mathrm{II})$ ions or $\mathrm{Ni}_{2} \mathrm{O}_{3}$, large amounts of oxygen evolution was detected in the presence of $\mathrm{Fe} / \mathrm{Ni}$ hydroxide or $\mathrm{Ni}(\mathrm{II})$ hydroxide and $\mathrm{K}_{2} \mathrm{FeO}_{4}$. These experiments show that:

(i) $\mathrm{Ni}_{2} \mathrm{O}_{3}$ is relatively stable at alkaline conditions.

(ii) $\mathrm{Ni}_{2} \mathrm{O}_{3}$ is relatively stable at alkaline conditions and in the presence of $\mathrm{Fe}(\mathrm{III})$.

(iii) $\mathrm{K}_{2} \mathrm{FeO}_{4}$ is more active toward OER than $\mathrm{Ni}_{2} \mathrm{O}_{3}$.

(iv) Significant OER is observed in the presence of $\mathrm{K}_{2} \mathrm{FeO}_{4}$ and $\mathrm{Ni}(\mathrm{II})$ hydroxide.

Why $\mathrm{Ni}(\mathrm{II})$ hydroxide and not $\mathrm{Ni}_{2} \mathrm{O}_{3}$ significantly induces the decomposition of $\mathrm{K}_{2} \mathrm{FeO}_{4}$ could be related to the presence of labile $\mathrm{Ni}$ (II) ions on the surface of $\mathrm{Ni}$ (II) hydroxide, which contrary to an inert $\mathrm{Ni}$ (III), quickly form an intermediate such as $\mathbf{1}$ shown in Fig. 8. As the research on OER by Ni/Fe oxides are focused on the electrochemical issues ${ }^{32-38}$, these chemical experiments could be a road map to new findings.

\section{Conclusions}

In the study, OER by $\mathrm{Ni}$ oxide in the presence of Fe ions under electrochemical conditions was investigated. $\left[\mathrm{FeO}_{4}\right]^{2-}$ was used as a new, soluble in $\mathrm{KOH}$, and colorful with negative charge Fe salt for investigating the effect of Fe on OER by nickel oxide. A Ni foam was operated at $10.0 \mathrm{~V}$, and then the Ni oxide/Ni interface was used for the electrochemical investigation.

In the absence of the Fe salt and the presence of the impurity in $\mathrm{KOH}$ or electrochemical cell, an increase in OER was displayed during the consecutive CVs. The Ni oxidation peak shifted from $1.43 \mathrm{~V}$ to $1.46 \mathrm{~V}$. After adding the Fe salt, a significant change is observed in OER, and the Ni oxidation peak is observed at $1.50 \mathrm{~V}$.

SWV indicated the clear peaks for $\mathrm{Ni}(\mathrm{II}) /(\mathrm{III})$ oxidation before and after adding the Fe salt. In the absence of the Fe salt in $\mathrm{KOH}(\mathrm{pH} \approx 13$ ), a peak at $1.37 \mathrm{~V}$ was observed, which corresponded to $\mathrm{Ni}(\mathrm{II}) / \mathrm{Ni}$ (III) oxidation. After 50 consecutive CVs, the peak shifted to $1.39 \mathrm{~V}$, which was attributable to the effect of Fe impurity. After adding the Fe salt, the peak was observed at $1.42 \mathrm{~V}$. The effect of different scan rates on OER, Ni oxidation and reduction peaks were also studied. Both oxidation and reduction peaks for $\mathrm{Ni}$ in the presence and absence of Fe changed linearly by (scan rate $)^{1 / 2}$. The oxidation peaks shifted to higher potentials, and reduction peaks shifted to the lower potential in the presence of Fe ions. Adding large amounts of the Fe salt had no significantly stronger effect on OER compared to adding a small amount of the Fe salt. SEM images of the foam as an anode electrode (amperometry at $1.46 \mathrm{~V}$ in $\mathrm{KOH}(\mathrm{pH} \approx 13)$ ), after adding the Fe salt, showed nanoparticles on the surface of the electrode (ca. $70-100 \mathrm{~nm}$ ). In the next step, OER of $\left[\mathrm{FeO}_{4}\right]^{2-}$ and $\mathrm{Ni}_{2} \mathrm{O}_{3}$ under chemical conditions was investigated. The experiments showed that $\mathrm{K}_{2} \mathrm{FeO}_{4}$, compared to $\mathrm{Ni}_{2} \mathrm{O}_{3}$, is more active toward OER. Significant OER is observed in the presence of $\mathrm{K}_{2} \mathrm{FeO}_{4}$ and $\mathrm{Ni}(\mathrm{II})$ hydroxide. 


\section{Methods}

See Supplementary Information

Received: 29 February 2020; Accepted: 23 April 2020;

Published online: 29 May 2020

\section{References}

1. Lewis, N. S. \& Nocera, D. G. Powering the planet: Chemical challenges in solar energy utilization. PNAS 103, 15729-15735, https:// doi.org/10.1073/pnas.0603395103 (2006).

2. Wang, Q. \& Domen, K. Particulate photocatalysts for light-driven water splitting: mechanisms, challenges, and design strategies. Chem. Rev., https://doi.org/10.1021/acs.chemrev.9b00201 (2019).

3. Najafpour, M. M. et al. Manganese compounds as water-oxidizing catalysts: from the natural water-oxidizing complex to nanosized manganese oxide structures. Chem. Rev. 116, 2886-2936, https://doi.org/10.1021/acs.chemrev.5b00340 (2016).

4. Wiechen, M., Najafpour, M., Allakhverdiev, S. I. \& Spiccia, L. OER catalysis by manganese oxides: learning from evolution. Energy Environ. Sci. 7, 2203-2212, https://doi.org/10.1039/C4EE00681J (2014).

5. Rüttinger, W. \& Dismukes, G. C. Synthetic water-oxidation catalysts for artificial photosynthetic water oxidation. Chem. Rev. 97, 1-24, https://doi.org/10.1021/cr950201z (1997).

6. Yagi, M. \& Kaneko, M. Molecular catalysts for water oxidation. Chem. Rev. 101, 21-36, https://doi.org/10.1021/cr9801081 (2001).

7. Blakemore, J. D., Crabtree, R. H. \& Brudvig, G. W. Molecular catalysts for water oxidation. Chem. Rev. 115, 12974-13005, https:// doi.org/10.1021/acs.chemrev.5b00122 (2015).

8. Hunter, B. M., Gray, H. B. \& Muller, A. M. Earth-abundant heterogeneous water oxidation catalysts. Chem. Rev. 116, 14120-14136, https://doi.org/10.1021/acs.chemrev.6b00398 (2016).

9. Tichenor, R. L. Nickel oxides-relation between electrochemical and foreign ion content. Ind. Eng. Chem. Res. 44, 973-977, https:// doi.org/10.1021/ie50509a022 (1952).

10. Troilius, G. A. G. Power Sources. 5th edn, 337 (Pergamon Press, Oxford, 1966).

11. Corrigan, D. A. The catalysis of the oxygen evolution reaction by iron impurities in thin film nickel oxide electrodes. J. Electrochem. Soc. 134, 377-384, https://doi.org/10.1149/1.2100463 (1987).

12. Trotochaud, L., Young, S. L., Ranney, J. K. \& Boettcher, S. W. Nickel-iron oxyhydroxide oxygen-evolution electrocatalysts: the role of intentional and incidental iron incorporation. J. Am. Chem. Soc. 136, 6744-6753, https://doi.org/10.1021/ja502379c (2014).

13. Beverskog, B. \& Puigdomenech, I. Revised pourbaix diagrams for iron at 25-300 ${ }^{\circ}$ C. Corros Sci. 38, 2121-2135, https://doi. org/10.1016/S0010-938X(96)00067-4 (1996).

14. Beverskog, B. \& Puigdomenech, I. Revised Pourbaix diagrams for nickel at 25-300 ${ }^{\circ}$ C. Corros Sci. 39, 969-980, https://doi. org/10.1016/S0010-938X(97)00002-4 (1997).

15. Friebel, D. et al. Identification of highly active Fe sites in (Ni, Fe) OOH for electrocatalytic water splitting. J. Am. Chem. Soc. 137, 1305-1313, https://doi.org/10.1021/ja511559d (2015).

16. Klaus, S., Cai, Y., Louie, M. W., Trotochaud, L. \& Bell, A. T. Effects of Fe electrolyte impurities on $\mathrm{Ni}(\mathrm{OH})_{2} / \mathrm{NiOOH}$ structure and oxygen evolution activity. J. Phys. Chem. C 119, 7243-7254, https://doi.org/10.1021/acs.jpcc.5b00105 (2015).

17. Kamber, D. N. et al. 1, 2, 4-triazines are versatile bioorthogonal reagents. J. Am. Chem. Soc. 137, 8388-8391, https://doi.org/10.1021/ jacs.5b05100 (2015).

18. Ahn, H. S. \& Bard, A. J. Surface interrogation scanning electrochemical microscopy of $\mathrm{Ni}_{1-\mathrm{x}} \mathrm{Fe}_{\mathrm{x}} \mathrm{OOH}(0<\mathrm{x}<0.27)$ oxygen evolving catalyst: Kinetics of the "Fast" iron sites. J. Am. Chem. Soc. 138, 313-318, https://doi.org/10.1021/jacs.5b10977 (2016).

19. Drevon, D. et al. Uncovering the role of oxygen in $\mathrm{Ni}-\mathrm{Fe}(\mathrm{OxHy})$ electrocatalysts using in situ soft $\mathrm{x}$-ray absorption spectroscopy during the oxygen evolution reaction. Sci. Rep. 9, 1-11, https://doi.org/10.1038/s41598-018-37307-x (2019).

20. Chen, J. Y. et al. Operando analysis of $\mathrm{NiFe}$ and $\mathrm{Fe}$ oxyhydroxide electrocatalysts for water oxidation: detection of Fe ${ }^{4+}$ by $\mathrm{Mossbauer}$ spectroscopy. J. Am. Chem. Soc. 137, 15090-15093, https://doi.org/10.1021/jacs.5b10699 (2015).

21. Boettcher, S. W. Oxygen stays put during water oxidation. Nat. Catal. 1, 814-815, https://doi.org/10.1038/s41929-018-0179-1 (2018).

22. Roy, C. et al. Impact of nanoparticle size and lattice oxygen on water oxidation on $\mathrm{NiFeO}_{\mathrm{x}} \mathrm{H}_{\mathrm{y}}$ Nat. Catal. 1, 820-829, https://doi. org/10.1038/s41929-018-0162-x (2018).

23. Lee, S., Banjac, K., Lingenfelder, M. \& Hu, X. Oxygen isotope labeling experiments reveal different reaction sites for the oxygen evolution reaction on nickel and nickel iron oxides. Angew. Chem. 131, 10401-10405, https://doi.org/10.1002/ange.201903200 (2019).

24. Ye, J.-M., He, D.-H., Li, F., Li, Y.-L. \& He, J.-B. Roles of soluble species in the alkaline oxygen evolution reaction on a nickel anode. ChemComm 54, 10116-10119, https://doi.org/10.1039/C8CC05896B (2018).

25. Veprek, J. Siska and V. Ettel. Chem. Ind. 1967, 548 (1967).

26. Hunter, B. M. et al. Trapping an iron (VI) water-splitting intermediate in nonaqueous media. Joule 2, 747-763, https://doi. org/10.1016/j.joule.2018.01.008 (2018).

27. Wulfsberg, G. Principles of descriptive inorganic chemistry. (University Science Books, 1991).

28. Grosvenor, A. P., Biesinger, M. C., Smart, R. S. C. \& McIntyre, N. S. New interpretations of XPS spectra of nickel metal and oxides. Surf. Sci. 600(9), 1771-1779, https://doi.org/10.1016/j.susc.2006.01.041 (2006).

29. Najafpour, M. M. \& Moghaddam, N. J. An efficient nickel oxides/nickel structure for water oxidation: a new strategy. New J. Chem 41, 1909-1913, https://doi.org/10.1039/C6NJ02842J (2017).

30. Bediako, D. K. et al. Structure-activity correlations in a nickel-borate oxygen evolution catalyst. J. Am. Chem. Soc. 134, 6801-6809, https://doi.org/10.1021/ja301018q (2012).

31. Schmidbaur, $\mathrm{H}$. The history and the current revival of the oxo chemistry of iron in its highest oxidation states: $\mathrm{Fe}_{\mathrm{VI}}-\mathrm{Fe}_{\mathrm{VIII}} \cdot \mathrm{Z}$. Anorg. Allg. Chem. 644, 536-559, https://doi.org/10.1002/zaac.201800036 (2018).

32. Najafpour, M. M. et al. An aluminum/cobalt/iron/nickel alloy as a precatalyst for water oxidation. Int. J. Hydrog. Energy 43, 2083-2090, https://doi.org/10.1016/j.ijhydene.2017.12.025 (2018).

33. Najafpour, M. M. \& Moghaddam, N. J. Iron oxide deposited on metallic nickel for water oxidation. Sustain. Energy Fuels 1, 658-663, https://doi.org/10.1039/C7SE00064B (2017).

34. Mehrabani, S. et al. Nanosized $\left(\mathrm{Ni}_{1-\mathrm{x}} \mathrm{Zn}_{\mathrm{x}}\right) \mathrm{Fe}_{2} \mathrm{O}_{4}$ for water oxidation. Nanoscale Adv. 1, 686-695, https://doi.org/10.1039/ C8NA00200B (2019).

35. Madadkhani, S. et al. A trimetallic organometallic precursor for efficient water oxidation. Sci. Rep. 9, 1-8, https://doi.org/10.1038/ s41598-019-40236-y (2019).

36. Liu, Z., Zha, M., Wang, Q., Hu, G. \& Feng, L. Overall water splitting reaction efficiently catalyzed by a novel bi-functional Ru/Ni3NNi electrode. Chem Comm, https://doi.org/10.1039/C9CC09187D (2020).

37. Chen, S. et al. FeNi intermetallic compound nanoparticles wrapped by N-doped graphitized carbon: A novel cocatalyst for boosting photocatalytic hydrogen evolution. J. Mater. Chem. A, https://doi.org/10.1039/C9TA12915D (2020).

38. Zhang, X. et al. $\mathrm{FeNi}_{3}$ modified $\mathrm{Fe}_{2} \mathrm{O}_{3} / \mathrm{NiO} / \mathrm{MoO}_{2}$ heterogeneous nanoparticles immobilized $\mathrm{N}$, $\mathrm{P}$ co-doped CNT as efficient and stable electrocatalyst for water oxidation. Nanoscale, https://doi.org/10.1039/C9NR09460A (2020). 


\section{Acknowledgements}

The authors are grateful to the Institute for Advanced Studies in Basic Sciences and the National Elite Foundation for their financial support. This research was also supported by the Ningbo Municipal Natural Science Foundation (Grant No. 2018A610183).

\section{Author contributions}

M.M.N. proposed the concept. M.S.A.A. and R.B. performed the experiments. All authors analyzed data. M.M.N. wrote the paper.

\section{Competing interests}

The authors declare no competing interests.

\section{Additional information}

Supplementary information is available for this paper at https://doi.org/10.1038/s41598-020-65674-x.

Correspondence and requests for materials should be addressed to M.M.N.

Reprints and permissions information is available at www.nature.com/reprints.

Publisher's note Springer Nature remains neutral with regard to jurisdictional claims in published maps and institutional affiliations.

(c) (i) Open Access This article is licensed under a Creative Commons Attribution 4.0 International License, which permits use, sharing, adaptation, distribution and reproduction in any medium or format, as long as you give appropriate credit to the original author(s) and the source, provide a link to the Creative Commons license, and indicate if changes were made. The images or other third party material in this article are included in the article's Creative Commons license, unless indicated otherwise in a credit line to the material. If material is not included in the article's Creative Commons license and your intended use is not permitted by statutory regulation or exceeds the permitted use, you will need to obtain permission directly from the copyright holder. To view a copy of this license, visit http://creativecommons.org/licenses/by/4.0/.

(c) The Author(s) 2020 